\title{
ROLE OF BOSWELLIC ACID IN THE TREATMENT OF PEPTIC ULCER DISEASE
}

\author{
Mai Sherif $^{1 *}$, Rehab Kamel ${ }^{2}$, Enjy Elmorsy ${ }^{2}$, Sherifa K. Ahmed ${ }^{1}$ \\ ${ }^{1}$ Department of Toxicology , National Organization For Drug Control And Research , \\ Giza, Egypt \\ ${ }^{2}$ Department of Pharmacology, Faculty of Pharmacy, Helwan University, Cairo, Egypt
}

\section{Corresponding author : MaiMohie@outlook.com}

\begin{abstract}
A peptic ulcer is a chronic disease. Its main features are the incompetent defense of the mucosal and the existence of the gastric juice. The two most important factors that disrupt the balance between the acid and the mucus are the Helicobacter pylori infection (H. pylori) and Non-steroidal anti-inflammatory drugs (NSAIDs). The known treatments like proton pump inhibitors (PPIs) and histamine-2 (H2) receptor antagonists have demonstrated adverse effects and various drug interactions. So the desired approach nowadays is alternative therapies and the usage of herbal products. Boswellic acids provide a potential alternative to the treatment of non-steroidal anti-inflammatory drugs induced peptic ulcer.
\end{abstract}

Keywords: Peptic ulcer, Boswellic acid, Matrix metalloproteinase, Indomethacin, Antioxidant

\section{Peptic ulcer disease}

The peptic ulcer is deterioration in the gastric or duodenal mucosa down to the submucosa. Peptic Ulcer Disease (PU) is a complex and multi-causal disease .The various causes of gastric ulcers are stress, trauma, Helicobacter pylori infection, use of alcohol and cigarettes, and steroidal and non-steroidal anti-inflammatory drugs (NSAIDs) (Takeuchi, 2012; Karaoğlan et al., 2018).

The peptic ulcer occurs due to an imbalance between mucosal defense factors and harmful factors. Defense factors are bicarbonate, mucin (Allen and Garner, 1980), healthy blood flow (Borrelli and Izzo, 2000), prostaglandins (Cryer, 2001), nitric oxide (NO) (Rahal et al., 2014). They also include antioxidant enzymes such as catalase, Glutathione (GSH) (Repetto and Llesuy, 2002), peptides, and growth factors (Szabo et al., 2000).

Injurious factors are acid, pepsin (Borrelli and Izzo, 2000), reactive oxygen species generation (Repetto and Llesuy, 2002), leukotrienes, prostaglandin inhibitors (Wallace et al., 1990), endothelins (Borrelli and Izzo, 2000), and extracellular matrix (ECM) degradation in which matrix metalloproteinases (MMPs) play a vital role (Frankowski et al., 2012).. 
Most of the gastric lesions originate in a chronic infection of gastric mucosa with Helicobacter pylori (H.P). H.P is a universal human pathogen with asymptomatic stomach colonization in nearly $70 \%$ of the population, and approximately $10-20 \%$ are susceptible to PU (Vitor and Vale, 2011).

Under normal circumstances, the stomach can withstand highly concentrated hydrochloric acid, reflux bile salts, alcohol, and food with varying temperatures and osmolarities; because the mucosal layer of the stomach can repair rapidly the damage caused by the harmful influences. The production of PGs is found to modulate many aspects of the mucosal defense, thereby enhancing the resistance of the stomach layer (Nur Azlina et al. 2015).

PGs of gastric epithelium and duodenum directly control the mucus and bicarbonate secretions, the mucosal blood flow, the proliferation of the epithelial cell, the epithelial restitution, and the mucosal immunocyte function (Wallace, 2000). By the mechanisms mentioned above, the PGs defend the mucosal lining. However, nitric oxide (NO) can also carry the same function (Wallace and Tigley, 1995). Thus, the suppression of PGs alone does not lead to damage to gastric mucosal (Langenbach et al., 1995). Bioactive PGs production requires the enzyme cyclooxygenase (COX) either COX1 (constitutive) or COX2 (inducible). Aspirin and indomethacin are examples of pain killer drugs in the NSAIDs group. In short, NSAIDs will inhibit the enzyme COX no selectively (Nafeeza et al., 2002), resulting in stunted PGs production (Shimada et al., 2004).

\section{Non-steroidal anti-inflammatory (NSAI) drugs induced peptic ulcer}

One-third of patients who are permanently taking NSAIDs suffer from gastric or duodenal ulcers (Jones et al. 2008). Furthermore, the annual costs of direct and indirect NSAID-related adverse effects are estimated to exceed 7 billion $\$$ in the United States (Delco et al., 2004). Highly selective cyclooxygenase (COX)-2 inhibitors with an improved gastric tolerability profile have been developed (Silverstein et al., 2000). However, severe cardiovascular adverse reactions and market withdrawals of some coxibs have reduced the initial enthusiasm for this new class of anti-inflammatory drugs (Farooq et al., 2008; Graham et al., 2005).

On the other hand, Indomethacin has higher ulcerogenic potential than other NSAIDs. Thus it was considered as the drug of choice for gastric ulcer experimental induction (Suleyman et al., 2010). Chatterjee et al., (2012) concluded that anti-ulcer parameters such as the levels of prostaglandin E, cyclooxygenase (COX) 1 and 2 enzymes, anti-inflammatory cytokines (interleukin (IL)-4 and -5), pro-angiogenic factors, vascular endothelial growth factor, hepatocyte growth factor (HGF), and endothelial growth factor (EGF) were down-regulated by indomethacin.

NSAID drugs causes damage to the stomach tissue by inhibiting the secretion of cytoprotective prostaglandin, mucus, and bicarbonate. It also increases stomach acid secretion. The COX-2 enzyme is responsible for the anti-inflammatory impact of indomethacin, while COX-1 enzyme inhibition is one of the reasons for the gastrointestinal toxic effects (Suleyman et al., 2007; Suleyman et al., 2010; Drini,2017). 
Naito et al. (1998) reported that the amounts of malondialdehyde (MDA) and myeloperoxidase (MPO) have increased, as for the levels of glutathione and its enzymes, superoxide dismutase (SOD), catalase (CAT) have decreased in damaged stomach tissue. While for Albayrak et al. (2015) and Piao et al. (2018) have noted that that the Indomethacin has changed the oxidant-antioxidant balance in stomach tissue, which includes MDA, MPO, GST, SOD, and CAT.

Moreover, indomethacin caused a significant increase in the activation of nuclear transcription factor kappa $\mathrm{B}(\mathrm{NF}-\mathrm{\kappa B})$, matrix metalloproteinases- 9 and -2 , and the tissue inhibitor of metalloproteinase (TIMP)-1 and 2 (Singh et al., 2011; Ganguly and Swarnakar, 2012).

NSAIDs disturb the mucus phospholipids. They also lead to the uncoupling of mitochondrial oxidative phosphorylation. So, they initiate the damage of the mucosa. When exposed to the acidic environment of $\mathrm{pH} \mathrm{2,} \mathrm{they} \mathrm{become} \mathrm{protonated} \mathrm{and} \mathrm{cross}$ lipid membranes to enter epithelial cells, which have a $\mathrm{pH}$ of 7.4. Then they become ionized and release a proton. Then,NSAIDs are captured in the epithelial cells, thus cannot cross the lipid membrane, leading to the uncoupling of oxidative phosphorylation, decreasing the mitochondrial energy production, increasing the cellular permeability, and reducing the integrity of the cell. Patients, who have a history of peptic ulcers or hemorrhage (over 65 years, take high doses of NSAIDs, or use combinations of them) are at the highest risk of acquiring NSAIDs-induced ulcers. Those patients might also be using steroids or anticoagulants (Narayanan, 2018).

There is indisputable evidence that other prostaglandin-independent mechanisms are also involved. These include the generation of reactive oxygen species (ROS), initiation of lipid peroxidation, and infiltration of neutrophils secondary to the production of inflammatory mediators such as tumor necrosis factor-alpha (TNF- $\alpha$ ) and leukotrienes (Motawi et al., 2008). This means that the suppression of PGs alone does not cause damage to the gastric mucosa. NSAIDs will inhibit the production of the enzyme COX (Nafeeza et al., 2002), resulting in stunted PGs production (Shimada et al., 2004).

Matrix metalloproteinase (MMPs), especially proMMP-2 (72-kDa gelatinase A), proMMP-9 (92-kDa gelatinase B), and their active forms are associated with gastric injury (Frankowski et al., 2012). Although MMP-2 appears to be constitutively expressed by many cell types in culture, MMP-9 expression is induced during gastric ulcer development (Verma et al., 2014). In addition, MMP-1, 3 are also up regulated in gastric and duodenal ulcers. Other studies reported that NSAIDs increase MMP-9 activity and suppress MMP-2 activity during gastric ulcers. In chronic HP infection , MMP-2 activity also gets up regulated with MMP-9 ( Wroblewski et al., 2010). Thus, MMP-9 expression is crucial for the development of gastric ulcers, but MMP-2 may be involved in the turnover of gastric ECM. Cheng et al. (2012) reported the up regulation of MMP-1 and MMP-9 during H. pylori infection in cultured cells. Acetic acid-induced experimental ulcer also showed up regulation of MMP-9, but there was no significant change in the expression of MMP-2 (Cheng et al., 2004). 
Besides, the infection can also influence the up regulation of MMP-1, 2, 3, and 7 , but the mechanisms and pathways are not yet well understood. In contrast, in Hydrogen Peroxide-mediated ulcers, MMP-2 activity expression gets down regulated (Ganguly et al., 2006, Kar et al. (2010) demonstrated that Hydrogen peroxide alters the structure of MMP-2 by oxidation and catalytic domain inhibition. Singh et al., 2011 proclaimed that proMMP-9, along with pro and active MMP-2 gets up regulated in ethanol-induced gastric ulcers in experimental rats. Thus, the critical balance of MMP-9 and MMP-2 activities may be a determinant in the progression as well as the healing of gastric ulcers. However, the functional overlap between the MMPs leads to nonspecificity, which makes designing MMP inhibitors more difficult. Thus, specific MMP inhibitors would be a promising therapeutic tool against inflammatory diseases, including gastric disorders (Chakraborty et al., 2012).

NSAIDs intake is associated with a high prevalence of gastrointestinal or cardiovascular adverse effects. All efforts to develop NSAIDs that spare the digestive tract and the cardio-vasculature are still far from achieving a breakthrough (AbdelTawab, 2011). Many studies showed micronized NSAIDs, at low dosages using nanotechnology, can increase the drug level and increase absorption and can have the best effect at the lowest dose and reduce the risk of side effects (Balakheyli etal,2019)

\section{Conventional drugs for peptic ulcer disease}

Proton pump inhibitors (PPIs) are among the most commonly used and overprescribed medications in the world (Spechler, 2019). The side effects of the PPIs, such as headache, diarrhea, nausea, abdominal pain, and constipation, are minor and easily managed. However, recent studies have suggested an association between PPI use and several serious adverse effects, which has been a source of significant concern to patients and physicians.

Some of the adverse effects of PPIs are related to their suppression of gastric acid secretion, allowing ingested microbial pathogens that would have been destroyed by gastric acid to colonize the upper gastrointestinal tract and cause infections. Reports are suggesting that the use of PPIs might increase the risk of enteric diseases such as Salmonella and Campylobacter, community-acquired pneumonia (Lambert et al., 2019), Clostridium complicated infections (Kwok et al., 2012), and spontaneous bacterial peritonitis (Deshpande et al.,2013).

Ghebremariam et al. (2014) mentioned that there is a dramatic increase in reports of miscellaneous unanticipated adverse effects of PPIs over the past several years, such as myocardial infarction, stroke, eosinophilic esophagitis acute, and chronic kidney disease. Many pathophysiological hypotheses have been proposed to explain cardiovascular events, renal failure, and neurological defects potentially induced by PPIs. Gilard et al. (2006) suggested the decreased production of nitric oxide and altered vascular homeostasis. Kheloufi et al., (2018) pointed out the three primary mechanisms that could conduct to high vascular risk, nephrotoxicity, and dementia, they are i) increase of endothelial senescence, ii) endothelial dysfunction, and iii) lysosomal acidification impairment associated with impaired proteostasis. Yepuri et al. (2016) announced that using human endothelial cells in the chronic exposure of esomeprazole 
led to endothelial senescence linked to telomere attrition and oxidative stress. Furthermore, nephrotoxicity of PPIs could be due to defects of lysosomal acidification, proteostasis, and hypomagnesemia, causing oxidative stress and leading to renal endothelial cell dysfunctions.

The increased frequency of cardiovascular events, while using Clopidogrel with PPIs, can be the result of the drugs competing for metabolism by CYP2C19, although there is a possibility that PPIs might have cardiovascular effects that are independent of their effects on clopidogrel activation by the mechanism of decreasing the production of nitric oxide, which alters the vascular homeostasis. The clinical importance of the interaction remains disputed, but the Food and Drug Administration (FDA) has issued warnings to avoid using omeprazole or esomeprazole with clopidogrel. (Arif, 2017).

PPI-induced hypergastrinemia in humans generally is mild, and rarely causes carcinoid tumors in human patients unless they have a genetic abnormality. Not to mention, PPI usage might protect against cancer in Barrett's esophagus, since PPIs heal the chronic esophageal inflammation of reflux esophagitis, which is a risk factor for the development of malignancy (Laine et al., 2000).

Gastric acid inhibition by PPIs also can affect the uptake of specific vitamins, minerals, and medications. There are reports of patients on PPIs developing vitamin B12 deficiency and iron deficiency anemia (Lam et al., 2013). Additionally, PPIs might increase the risk for osteoporosis and bone fractures by interfering with the ionization and solubilization of the calcium salts that are required for their absorption (Koivisto et al., 2005). PPI-induced gastric acid suppression decreases ketoconazole absorption and facilitates the absorption of digoxin as well (Lanas, 2016; Lew, 1999).

In such a manner, investigations of the new pharmacologically active agents through screening different plant extracts led to the discovery of effective and safe drugs with gastroprotective activity. Mainly, plants with antioxidant capability as the primary mechanism are used as the herbal reservoir for the treatment of ulcer disease (Palle et al., 2018).

It is known that numerous pharmaceutical agents such as proton pump inhibitors, anticholinergics, antacids, antimicrobial agents, H2-receptor antagonists, sucralfate, and bismuth are not sufficiently active. They also produce numerous adverse effects such as impotence, arrhythmia, hematopoietic alterations, hypersensitivity, and gynecomastia (Chanda et al., 2011; Palle et al. ,2018). Medicinal plants are the primary source of new drug candidates for the treatment of gastric ulcers. The medicines are considered safer because of the natural ingredients with no or fewer side effects. The usage of medicinal plants in healing numerous diseases is as old as human beings and well-known as phytotherapy. Moreover, in the past few years, there has been a rising interest in alternative therapies and the usage of herbal products, in particular, those produced from medicinal plants (Rates, 2001; Falcão et al.,2008).

Medicinal plants are widely used to treat different life-threatening ailments. Traditional herbal medicine has not only an essential role in healing but also contributes to the research on the development of most pharmaceutically important metabolites 
from plants, which are helpful to produce drugs on a commercial scale. Buyel (2018) noted that $90 \%$ population of developing countries depends on medicinal plants for primary health care and medicines.

\section{Boswellic acid}

Boswellia species resin holds about 60-80\% alcohol-soluble resin, $15-20 \%$ water-soluble gum, and 5-7\% essential oil. Also, polysaccharides fraction and polymeric substances are present to a limited extent. There are various active phytocompounds found in Boswellia species. The quantity and quality of these compounds change from species to species, which make the species different from another. The reasons behind these differences are related to the climate, harvesting time, and geographical conditions (Ammon, 2011).

Traditional medicine used Oleo-gum-resin of Boswellia serrata (BS) in the treatment of inflammatory diseases. Also, the standard oleo-gum-resin generally consists of terpenoids, phenolic compounds, flavonoids, triterpenoid principles, essential oils, and carbohydrates. The pentacyclic triterpenic acids isolated from the oleo gum resin of various Boswellia species are collectively called as Boswellic acids (BA). The resin has attracted pharmacological interest for its therapeutic potential against arthritis, asthma, colitis, Crohn's disease, and cancer. It is considered a promising alternative to the non-steroidal anti-inflammatory drug ( Moussaieff and Mechoulam, 2009; Morikawa et al.,2017 ; Bertocchi et al. 2018).

Boswellic acids have long been considered the main bioactive components of frankincense, and many studies in vitro, in vivo, as well as clinical studies have confirmed their massive bioactive spectrum like their anti-inflammatory and antitumor activities. However, not every BA exhibits a satisfactory pharmacological performance, which depends on the chemical structure and functional groups of the acid. The way to enhance the pharmacological values of Boswellic acids is derivatization to discover more active by-products. However, the preliminary pharmacokinetic studies of these compounds using various standard methods show their poor bioavailability in humans and rodents, which limit their use in clinical practice and pharmaceutical development. Fortunately, some approaches have shown some improvements, and the new formula compatibility advance is considered a very reasonable method for improving the bioavailability of BAs (Du et al., 2015).

The physicians and nutritionists have an interest in frankincense due to the therapeutic qualities of its gum resin and essential oil. It has a broad range of medicinal properties. Both gum resin and essential oil of various species of Boswellia like B. Serrata and B. carterii have been used to make a remedy to treat rheumatic and inflammatory diseases (Iram et al., 2017). Furthermore, there are several reports related to the use of extracts and essential oils of frankincense gum resin as an antibacterial and antiseptic in mouthwash as well as in remedy used to treat asthma and coughs (Banno et al., 2006). Various studies have described the anticancer, immunomodulatory, antiinflammatory, antimicrobial, anti-diabetic, and antiviral activities of several Boswellia (Sabra et al., 2014 ).In contrast, other reports indicated an insignificant effect of B. Serrata in persistent diseases (Holtmeier et al.,2010). 


\section{Pharmacological properties of Boswellia acids}

Early studies suggested that the anti-inflammatory activity of Boswellia acids is due to interference with the production of leukotrienes, which play a vital role in the pathogenesis of inflammation (Husch et al., 2013). BAs selectively inhibit the key enzyme of leukotriene synthesis, 5-lipoxygenase (Mostafa et al., 2017). Abdel-Tawab et al. (2011) found that other BAs such as b-BA could also play an important role, targeting the microsomal prostaglandin E2 synthase-1 as well as cathepsin G. Side effects of BAs include abdominal discomfort, nausea, epigastric pain, hyperacidity, and diarrhea (Gupta et al.,1998 ). Boswellic acid from B. Serrata has similar effects of NSAIDs, but with a different mechanism of action than those of the conventional NSAIDs (Safayhi et al., 1997).

Abdel-Tawab et al. (2011) indicated that many pharmacokinetic studies had confirmed the fact that the bioavailability of BAs, especially KBA and AKBA, is low due to the hindered systemic absorption, both in animals and in humans. In this context, Sterk et al. (2004) mentioned the beneficial effects of a fatty meal on the bioavailability of BAs combined with the improvement of absorption lately reported for a novel lecithin formulation of curcumin. It encouraged the researchers to compare the bioavailability of BAs in a soy lecithin formulation of the extract of B. Serrata with the unformulated extract.

Husch et al. (2013) reported that a new data on the tissue distribution of BAs were provided through measurement of the concentration of the six primary BAs in plasma as well as in different organs (brain, muscle, eye, liver, and kidney). The lecithin formulation exhibited a significant improvement in the absorption of BAs, leading to an increase in their tissue penetration. The concentration of these compounds in the questioned organs was in the same range to have the effect of their anti-inflammatory activity. So, these concentrations can establish the pharmacological actions of BAs, which in return, encourage further testing on humans. Several investigations have indicated that AKBA is the most active inhibitor of 5-LOX, an important enzyme to regulate cellular inflammation. The boswellic acid from B. carterii reduced inflammatory mediator's synthesis and restricted the formation of the leukotrienes by affecting 5-LOX (Safayhi et al., 1996). Boswellic acid inhibits either by direct react with 5-LOX or blocks its translocation. Since its Low production of leukotriene is the main target achieved as an anti-inflammatory agent. Additional, comprehensive inquiries exhibited Boswellia acids as non-redox inhibitors, which might provide a site for pentacyclic triterpenes on 5-LOX (Roy et al, 2019).

Henkel et al. (2015) demonstrated that the anti-inflammatory mechanism of BAs was related to the inhibition of antimicrobial peptide LL-37. Thus, BAs could be used as a potential drug to interfere with LL-37 and related diseases. Li et al. (2016) used frankincense oil extract (FOE) and its active components $\alpha$-pinene, linalool, and 1octanol to treat ear edema model and formalin inflamed posterior claw model mice. The results showed that they could significantly reduce swelling and pain and had potent local anti-inflammatory and analgesic effects. The possible mechanism is to inhibit the inflammatory infiltration induced by nociceptive stimulation and overexpression of cyclooxygenase-2 (COX-2). Boswellic acids also showed inhibition of prostaglandin, 
12 lipoxygenase, cytokines, and p-glycoprotein (Poeckel and Werz 2006). Ebrahimpour et al. (2017) studied the neuroprotective effect of Boswellic acid. He noted that the antioxidant activity of boswellic acid increases the capability of cognitive function in a rat model. Beghelli et al. (2017) showed that antioxidant power and phenolic content was noted in AKBA. Chen et al. (2016) observed that AKBA significantly augmented the activity of the antioxidant enzyme SOD and also reduced MDA and ROS. Barakat et al. (2018) demonstrated that Bas could eliminate ROS and inhibit lipid peroxide and DOX-induced hepatotoxic DNA damage. The antioxidant effect of Bas may be due to their regulation of the Nrf2/HO-1 pathway, thus protecting the liver from DOX-induced oxidative damage.

It has been confirmed that AKBA can regulate the activity of human collagenase MMP-1, MMP-2, and MMP-9. Therefore, the direct inhibition of MMP activity and the inhibition of MMP secretion may be one of the mechanisms of frankincense in the treatment of chronic skin ulcers (Liang et al., 2009). Singh et al. (2008) concluded that BA inhibits ulcer production non-specifically in all the experimental models: pyloric ligation, ethanol/ $\mathrm{HCl}$, indomethacin, cold restraint stress, acute, and chronic acetylsalicylic acid. It is possible that BA might be acting by increasing the gastric mucosal resistance and local synthesis of cytoprotective prostaglandins and inhibiting the leukotriene synthesis. Also, alpha-boswellic acid ( $\alpha$-BA), proved to be gastroprotective in ethanol-induced gastric injury in rats (Zhang et al., 2016). Riva et al. (2017) concluded that Boswellia serrata extracts have long been used for the treatment of musculoskeletal disorders, given their marked anti-inflammatory activity and their ability to promote tissue regeneration. Casperome, a lecithin-based formulation of Boswellia serrata extract, was effective in the treatment of Achilles tendonitis, epicondylitis, radiculopathies, ankle sprains, and sports injuries. All studies were consistent in showing a prompt decrease of pain and improvement of the functionality of the affected area after supplementation without any relevant adverse effect. Remarkably, these symptomatic improvements were paralleled by reduced plasmatic levels of inflammatory markers and by a diminished need for rescue analgesics.

Moreover, Forouzanfar (2016) stated that B. Serrata extracts prevent the increase of MDA levels, a marker of lipid peroxidation, and also increase GSH content and SOD activity in the cortex, which suggests antioxidant properties for B. Serrata after cerebral ischemia. Umar et al. (2014) proved that BA was effective in bringing significant changes to articular elastase, MPO, LPO, GSH, catalase, SOD And NO. Oral Administration of BAs Resulted in relatively reduced levels of IL-1, IL-6, TNF, IFN, PGE2, and the number of leucocytes. On the other hand, it showed an increased level of IL-10 and changed the electrophoretic pattern of the synovial fluid protein. Also, the author stated that the anti-inflammatory actions of BAs are due to the inhibition of leukotriene synthesis via 5-LOX; however, it has no effect on the activities of 12-LOX and the COX enzymes. Likewise, peroxidation of arachidonic acid by iron and ascorbate was also not impaired by BAs. B. Serrata extract is used in the treatment of chronic polyarthritis, as well. Kokkiripati et al. (2011) confirmed the antioxidant and antithrombotic anticoagulant activities of water and hydroalcoholic extracts of Boswellia Serrata's gum resin. 
BAs affect the cellular defense system by interaction with the production and release of cytokines. Thus, BAs inhibit activation of $\mathrm{NF \kappa B}$, which is a product of neutrophile granulocytes. Ammon, (2010) reported the downregulation of TNF- $\alpha$ and decrease of IL-1, IL-2, IL-4, IL-6, and IFN- $\gamma$, which are pro-inflammatory cytokines, by BAs. Moreover, the anti-inflammatory actions of BAs are caused by different mechanisms of action. They include inhibition of leukotriene synthesis, 5-lipoxygenase human leukocyte elastase, topoisomerase I, and II, IкB kinases, and prostaglandin synthesis. Furthermore, inhibition of the complement system at the level of conversion of $\mathrm{C} 3$ into $\mathrm{C} 3 \mathrm{a}$ and $\mathrm{C} 3 \mathrm{~b}$. A significant target of BAs is the immune system. BAs have been shown to decrease the production of pro-inflammatory cytokines, including IL-1, IL-2, IL-6, IFN- $\gamma$, and TNF- $\alpha$, which finally are directed to destroy tissues such as cartilage, insulin-producing cells, bronchial, intestinal and other tissues (Ammon, 2016; Iram et al., 2017).

The complex actions of BAs in inflamed areas may be completed by some effects that are localized behind the inflammatory process as tissue destruction. In this case, BAs suppress the proteolytic activity of cathepsin G, human leukocyte elastase, the formation of oxygen radicals, and lysosomal enzymes. BAs act on a variety of targets specifically on 5-LOX, topo-isomerases, angiogenesis, and cytochrome p450 enzymes. Besides, depending on the type of cell affected, BAs may stimulate or inhibit mitogen-activated protein kinase (MAPK), especially p38 (Ammon, 2016; Iram et al., 2017).

Khosravi et al. (2011) conducted a double-blind, randomized clinical trial to assess the efficacy of Boswellia in moderate plaque-induced gingivitis. They reported that Boswellia extract and powder could decrease the inflammation of periodontium associated with plaque-induced gingivitis due to their anti-inflammatory effects produced through multiple mechanisms. In other clinical trials, B. Serrata has also shown fair to excellent anti-inflammatory results in $88 \%$ of the patients, with no adverse side effects. It has also been reported that pure compounds from B. Serrata extract act as anti-inflammatory agents in human peripheral blood mononuclear cells (PBMCs) and mouse macrophages via inhibition of TNF-alpha, IL-1beta, NO and mitogen-activated protein (MAP) kinases (Gayathri et al., 2007).

Siemoneit et al. (2011); Verhoff et al. (2014) stated that the inhibition of prostaglandin (PG) synthesis is one of the primary mechanisms by which pharmaceutical agents produce their anti-inflammatory effect. Furthermore, they declared that BAs inhibit microsomal prostaglandin E2 synthase (mPGES)-1, which is an inducible enzyme belongs to three isoforms of PGE2 synthases and is responsible for the conversion of PGH2 to PGE2, which is the terminal enzyme in the biosynthesis of prostaglandin (PGE2) from cyclooxygenase (COX)-derived PGH2. Ammon (2010) described that the Inhibition of prostaglandin synthesis seems to play only a minor role as far as the anti-inflammatory effect of BAs is concerned. Contrary to this, the inhibition of 5-LOX by BAs decreases the production of leukotrienes. The scientific community has given that mechanism a considerable amount of attention since a variety of chronic inflammatory diseases are associated with increased leukotriene activity. Also, he stated that as compared to non-selective or cox-2-selective NSAIDs, mPGES-1 inhibitors would not damage the gastric mucosa, kidneys, or increase the risk for 
atheroma and vascular events. Indeed, such inhibitors might have a favorable impact on vascular health (save in the immediate aftermath of myocardial infarction). Therefore, the clinical dose of Boswellia acids, that are safe, also inhibits mPGES-1, are of significant importance. The possibility that these safe, natural and affordable agents used for centuries in traditional medicine may be useful for the prevention of cancer, vascular disease, and $\mathrm{AD}$, while also aiding control of pain and inflammation, is exciting indeed. However, when it comes to comparing the efficacy of Boswellia acids as an anti-inflammatory agent, which lowers the PGE2 by inhibiting the mPGES-1 with indomethacin, we will find that BAs are less potent, but suppress the exudate formation and infiltration of inflammatory cells, nonetheless (Ammon, 2010).

BAS (B-BA.Acetyl- B-BA;11-Keto- B-BA) showed gastric ulcer protective effects in different experimental models (Singh et al., 2008). Boswellia serrata extract (BSE) containing 3-acetyl-11-keto- $\beta$-boswellic acid (AKBBA) with $\beta$-boswellic acid (BBA)were administered to 45 patients of osteoarthritise for 120 days significantly improved the physical function of the patients by reducing pain and stiffness compared with placebo. Radiographic assessments showed improved knee joint gap and reduced osteophytes (spur) confirming the efficacy of BSE (Majeed etal, 2019).

More that 100 -folds higher plasma concentrations have been determined for $\beta$ Boswellic acid, which inhibits microsomal prostaglandin E synthase-1, and the serine protease cathepsin $\mathrm{G}$. Then, these two enzymes might be reasonable molecular targets related to the anti-inflammatory properties of BSE(Abdel-Tawab, 2011)..

Given the results of clinical trials and the experimental data from in vitro studies of BSE, and the available pharmacokinetic and metabolic data on Boswellic acids, it underlines BSE as a promising alternative to NSAIDs, which warrants investigation in further pharmacological studies and clinical trials (Abdel-Tawab, 2011).

Nitric oxide (NO) is a mediator not only of gastrointestinal mucosal defense but also of its damage (Calatayud et al., 2001). The stomach produces NO by constitutive enzyme isoform (cNOS), which is cytoprotective. It produces another isoform, which is cytotoxic, by the inducible enzyme. In general, the endothelial and mucosal NOS isoforms produce low amounts of NO. However, the high quantity of NO produced by iNOS can damage the epithelium (Wallace \& Miller, 2000). On the other hand, a low concentration of NO derived from cNOS is involved in mechanisms maintaining the integrity of the gastric epithelium. More than that, it regulates gastric blood flow and directly stimulates gastric mucus secretion by activating soluble guanylate cyclase (Cho, 2001). Lanas (2008) assumes that the protective effect of NO is due to the inhibition of activation, adhesion, and migration of leukocytes in the inflammatory area.

Konturek et al. (2000) concluded that the increased production of NO, due to the overexpression of iNOS, is one of the mechanisms by which NSAIDs damages the gastric mucosa. Moreover, Motawi et al. (2008) reported that indomethacin decreases tissue cNOS-derived NO and increases iNOS-derived NO. Maity et al. (2009) reported that the reduction of constitutive nitric oxide synthase(cNOS) activity and overexpression of inducible nitric oxide synthase (iNOS) mediates the increased ulcerogenic response to indomethacin. Water extract of Boswellia serrata inhibits the 
LPS induced NO production by the activated rat peritoneal macrophages and show hepato-protective and reno-protective property. LPS-induced expression of inducible nitric oxide synthase (iNOS) was selectively inhibited by those BAs that interfered with LPS activity (Henkel et al., 2012).

Hartmann et al. (2014) stated that the nitric oxide levels and the expression of inducible nitric oxide synthase (iNOS) showed a significant increase in the colitis group compared to control groups $(\mathrm{p}<0.01)$. Both pretreatment and treatment with B. Serrata exhibited significantly reduced lipid peroxidation, nitric oxide, iNOS. It also showed improvements in tissue injury and anal sphincter pressure in animals with ulcerative colitis. The B. Serrata extract has protective anti-inflammatory and antioxidant effects that inhibit inflammatory mediators in acute experimental colitis. These results indicate that iNOS is expressed in the ulcer bed and that iNOS activity may play beneficial roles in the ulcer repair process, possibly by regulating inflammation (Hartmann et al., 2014).

Wang et al., (2015), found that $\beta$-BA significantly increases nitric oxide (NO) and cyclic guanosine 3', 5'-monophosphate (cGMP) levels in carotid aortas in blood static rats. These findings provide convincing evidence for the protective effects of $\beta$ BA on blood stasis induced endothelial dysfunction by the eNOS signaling pathway. In an attempt to assess the antiulcer properties of BAs, a study on the gastro-protective role of $\alpha$-BA was performed in ethanol-induced gastric injury in rats. The findings demonstrated that $\alpha$-BA decreased ethanol administration related injuries, gastric juice acidity, and the development of MDA, and improved CAT activity along with SOD activity and the level of NO and PGE-2 (Zhang et al.,2016)

\section{Pharmacokinetic Properties of Boswellic Acids}

BAs are the chief bioactive element of frankincense gum resin extract of Boswellia serrata are known for their anti-inflammatory effects. However, they suffer from poor bioavailability because of their hydrophobicity and poor water solubility. Various studies have established their bioactivities. However, to develop it as a successful candidate drug, its pharmacokinetic properties must be considered accurately. In this regard, the studies conducted have exhibited poor pharmacological performance. Both KBA and AKBA are extremely lipophilic drugs, which result in reduced absorption through the GIT, but they also exhibit high retention time. Preliminary pharmacokinetic studies have shown minimal concentrations of both AKBA and KBA in human plasma after administration of BSE (Iram et al., 2017).

Gerbeth et al. (2013) found that KBA and AKBA were absorbed in the intestinal tracts by passive diffusion and active transport absorption related to enzymes. AKBA is more active in vitro studies than KBA but undergoes much less absorption than KBA. However, a high-fat meal increases the absorption of both when taken toegther more than twice. There are a variety of chronic inflammatory diseases that respond to treatment with extracts from the resin of Boswellia species. Although the number of cases is small, their results are convincing and supported by the preclinical data. These studies include rheumatoid arthritis osteoarthritis, chronic colitis, ulcerative colitis, collagenous colitis, Crohn's disease, and bronchial asthma. We cannot expect that it would be a cure for these diseases but at least an improvement of symptoms in about 
$60-70 \%$ of the cases. The number and severity of side effects are deficient. The mostreported complaints are gastrointestinal symptoms. Allergic reactions are rare. Moreover, most authors report that treatment with BEs is safe, and the registered side effects in BE- and placebo groups are similar (Ammon, 2016).

Also, the elimination half-life of 11-Keto $\beta$-Boswellic acid (KBA), is reported to be approximately six hours. The patient should take BAs every six h p.o. to achieve maximum plasma levels. Further, he must take the BAs with a fatty meal as it significantly increases their plasma concentration (Skarke et al., 2012).

Some studies have proved that the administration of Boswellia extracts in a lecithin delivery form markedly enhance the serum levels and subsequent tissue deposition of BAs (Sharma et al., 2010). The study noted that the use of phospholipidsbased delivery systems enhanced absorption while reduces variability (Husch et al., 2012). Sharma et al. (2010) used a complexation technique to improve the pharmacokinetic profile, especially their poor absorption through the intestine for better bioavailability. The complex of BAs with phosphatidylcholine enhanced the uptake. The obtained results revealed significantly improved absorption property of the complex concerning BA, due to its amphiphilic nature. Because of the improved pharmacokinetic and enhanced bioavailability, the complex showed better anti-inflammatory and hypolipidemic activity. It established the superiority of the complex over plain BA.

Several studies clearly demonstrate the detection of six primary BAs namely $\alpha-$ Boswellic acid, $\beta$-Boswellic acid, acetyl- $\alpha$-Boswellic acid, acetyl $\beta$-Boswellic acid, 11 keto- $\beta$-Boswellic acid, 3-O-acetyl-11 keto- $\beta$-Boswellic acid in tissues of rats following the oral administration of $240 \mathrm{mg} / \mathrm{kg}$ Boswellia $(86.97 \mathrm{mg} / \mathrm{kg}$ total BAs) (Husch et al., 2013). BAs undergo extensive metabolism that accounts for their poor bioavailability in vivo. Phase one metabolism in the liver appears to be the major metabolic pathway for KBA, $\alpha$, and $\beta$-BA. Mono or polyhydroxylated derivates are the predominant metabolites of these BAs. Metabolism took place in non-acetylated BA, while the acetylated forms (AKBA, Acetyl- $\beta$-Boswellic acid, and Acetyl- $\alpha$-Boswellic Acid) are resistant (Gerbeth et al.; 2013). Shah et al. (2009) concluded that the metabolic pathway of AKBA is different from KBA as it deacetylates to a minor extent to yield KBA.

In spite of Low bioavilability of BAs,several human clinical trials using suitable doses provide improvement in different clinical application (table-1) 
Table-1 Application of boswellic acid in different phases of human completed clinical trials.

\begin{tabular}{|c|c|c|}
\hline Disease & Dosage/Clinical Outcomes & References \\
\hline Osteoarthritis $^{\mathrm{a}, \mathrm{B}}$ & $(500 \mathrm{mg}) / \downarrow$ pain-related symptoms & Haroyanetal,2018 \\
\hline Osteoarthritis ${ }^{b, C}$ & $\begin{array}{l}(100,250 \mathrm{mg}) / \downarrow \text { pain and } \uparrow \text { physical } \\
\text { functioning* }\end{array}$ & Sengupta etal 2008 \\
\hline Osteoarthritis $^{\mathrm{C}}$ & $(300-500 \mathrm{mg}) / \downarrow$ pain and stiffness* & Majeed,etal,2019 \\
\hline Knee arthritis ${ }^{\mathrm{c}, \mathrm{C}}$ & $(7.2 \mathrm{mg}) /$ good and satisfactoryeffect* & [Notarnicola etal,2016 \\
\hline Gonarthrosis ${ }^{\mathrm{c}, \mathrm{C}}$ & $(7.2 \mathrm{mg}) /$ highly effective* ${ }^{*}$ & Notarnicola etal,2011 \\
\hline Brain tumors ${ }^{A}$ & $(4200 \mathrm{mg}) / \downarrow$ cerebral edema* & Kirste,2011 \\
\hline Photoaged skin $^{\mathrm{C}}$ & $\begin{array}{l}(0.5 \%) / \text { well-tolerated withoutadverse } \\
\text { effects* }\end{array}$ & Calzavara-Pintonetal,2010 \\
\hline Crohn disease ${ }^{\mathrm{d}, \mathrm{C}}$ & (NIL)/well tolerated* & Gerhardt etal,2001 \\
\hline Diabetes $^{\mathrm{C}}$ & (NIL)/ $\uparrow$ blood HDL levels, and $\downarrow$ cholesterol* & Ahangarpour etal,2014 \\
\hline $\begin{array}{l}\text { Erythematous } \\
\text { eczema }\end{array}$ & (NIL)/improvement in symptoms* & Togni, etal,2014 \\
\hline Asthma $^{\mathrm{C}}$ & $(300 \mathrm{mg}) / \downarrow$ eosinophilic count and ESR* & Gupta,etal,1998 \\
\hline
\end{tabular}

Abbreviations: $a=\mathrm{BA}$ in combination with curcumin; $\mathrm{b}=5$-Loxin, a novel Boswellia serrata extract enriched with $30 \%$ AKBA; $\mathrm{c}=\mathrm{BA}$ in combination with methylsulfonylmethane; $d=$ Boswellia serrata extract H15;A= Phase I; B = Phase II; C = $\mathrm{NA}, \mathrm{HDL}=$ high density lipoprotein; $\mathrm{ESR}=$ erythrocyte sedimentation rate.

\section{REFERENCES}

Abdel-Tawab M, Werz O, Schubert-Zsilavecz M. (2011) Boswellia serrata: an overall assessment of in vitro, preclinical, pharmacokinetic, and clinical data. Clin Pharmacokinet;50:349-369

Albayrak A, Alp HH, Suleyman H. (2015) Investigation of antiulcer and antioxidant activity of moclobemide in rats. Eurasian J Med.;47:32.

Ahangarpour, A.; Heidari, H.; Fatemeh, R.A.; Pakmehr, M.; Shahbazian, H.; Ahmadi, I.; Mombeini, Z.; Mehrangiz, B.H. (2014) Effect of Boswellia serrata supplementation on blood lipid, hepatic enzymes and fructosamine levels in type2 diabetic patients. J. Diabetes Metab. Disord. , 13, 29

Ali EN, Mansour SZ. (2011) Boswellic acids extract attenuates pulmonary fibrosis induced by bleomycin and oxidative stress from gamma irradiation in rats. Chin Med.; Sep 30;6:36. DOI: 10.1186/1749-8546-6-36

Allen A, Garner A. (1980) Mucus, and bicarbonate secretion in the stomach and their possible role in mucosal protection. Gut.; Mar;21(3):249-62.

Ammon HP. (2016) Boswellic Acids and Their Role in Chronic Inflammatory Diseases. Adv Exp Med, Biol.;928:291-327 
Ammon HP. (2011) Modulation of the immune system by Boswellia serrata extracts and Boswellic acids. Phytomedicine,;18(4):334.

Ammon HP, (2010) Modulation of the immune system by Boswellia serrata extracts and Boswellic acids. Phytomedicine. ;Sep;17(11):862-867.

Arif F. (2017) Nephrotoxic potential of proton pump inhibitors. Eur J Intern Med.; Apr 1. pii: S0953-6205(17)30125.

Banno N, Akihisa T, Yaskawa K, Tokuda H, Tabata K, Nakamura Y, Nishimura R, Kimura Y, Suzuki T. (2006) Anti-inflammatory activities of the triterpene acids from the resin of Boswellia carterii. J Ethnopharmacol;107: 249-253.

Balakheyli H. Abdolahi N; Soltani A; (2019) Erfani-MoghadamV;Rad SM; FRI0139 IMPROVEMENT SOLUBILITY OF AMPHIPHILIC NAPROXENNIOSOME FOR INFLAMMATORY ARTHRITIS TREATMENT; Poster Presentations Friday, 14 June;Rheumatoid arthritis - non biologic treatment

Barakat BM, Ahmed HI, Bahr HI, Elbahaie A M. (2018) Protective Effect of Boswellic Acids against Doxorubicin-Induced Hepatotoxicity: Impact on Nrf2/HO-1 Defense Pathway. Oxidative Med. Cell. Longev.;2018, 8296451.

Beghelli D, Isani G, Roncada P, Andreani G, Bistoni O, Bertocchi M, Lupidi G, Alunno A. (2017) Antioxidant and ex vivo immune system regulatory properties of Boswellia serrata extracts. Oxid Med Cell Longev;2017:7468064

Bertocchi M, Isani G, Medici F, Andreani G, Usca IT, Roncada P, Forni M, and Bernardini C. (2018) Anti-Inflammatory Activity of Boswellia serrata Extracts: An In Vitro Study on Porcine Aortic Endothelial Cells. Oxid Med Cell Longev.; 2018: 2504305.

Bishnoi M, Patil CS, Kumar A, Kulkarni SK. (2005) Protective effects of nimesulide (COX Inhibitor), AKBA (5-LOX Inhibitor), and their combination in agingassociated abnormalities in mice. Methods Find Exp Clin Pharmacol. ;Sep;27(7):465-470

Borrelli F, Izzo AA.(2000) The plant kingdom as a source of anti-ulcer remedies. Phytother Res.; Dec; 14(8):581-91.

Buyer JF. (2018) Plants as sources of natural and recombinant anti-cancer agents. Biotechnol Adv;18:9734-9750.

Calatayud S, Barrachina D, Esplugues JV. (2001) Nitric oxide: relation to integrity, injury, and healing of the gastric mucosa. Microsc Res Tech.; Jun 1;53(5):325335. 
Calzavara-Pinton, P.; Zane, C.; Facchinetti, E.; Capezzera, R.; Pedretti, A. (2010) Topical Boswellic acids for treatment of photoaged skin. Dermatol. Ther. , 23 (Suppl 1), S28-S32

Chanda S ,Baravalia Y, Kaneria M. (2011) Protective effect of Polyalthia longifolia var. Pendula leaves on ethanol and ethanol/HCL induced ulcer in rats and its antimicrobial potency. Asian Pac. J. Trop. Med., 4, 673-679.

Chakraborty S, Stalin S, Das N, Choudhury ST, Swarnakar Ghosh S S (2012) The use of nano-quercetin to arrest mitochondrial damage and MMP-9 upregulation during the prevention of gastric inflammation induced by ethanol in the rat. Biomaterials 2012; 33:2991-3001PubMedCrossRefGoogle Scholar

Chatterjee A, Chatterjee S, Das S, Saha A, Chattopadhyay S, (2012) Bandyopadhyay SK. Ellagic acid facilitates indomethacin-induced gastric ulcer healing via COX-2 up-regulation. Acta Biochim Biophys Sin (Shanghai).; Jul;44(7):565-576.

Chen M, Wang M, Yang Q, Wang M, Wang Z, Zhu Y, Zhang Y, Wang C, Jia Y, Li Y, Wen A. (2016) Antioxidant effects of hydroxysafflor yellow A and acetyl-11-keto-b-boswellic acid in combination on isoproterenol-induced myocardial injury in rats. Int J Mol Med;37(6):1501-1510.

Cheng HC, Yang HB, Chang WL, Chen WY, Yeh YC, ( 2012) Sheu BS.Expressions of MMPs and TIMP-1 in gastric ulcers may differentiate H. pylori-infected from NSAID-related ulcers. Sci World J .;ID 539316:9Google Scholar.

Cheng CL, Guo JS, Luk J, (2004) Koo MWL.The healing effects of Centella and asiaticoside on acetic acid-induced gastric ulcers in rats. Life Sci.; 74(18):2237-2249.

Cryer, B. (2001) Mucosal defense, and repair. Role of prostaglandins in the stomach and duodenum. Gastroenterol. Clin. North. Am.,; 30: 877-894.

Drini M. (2017) Peptic ulcer disease and non-steroidal anti-inflammatory drugs. Aust Prescr. Jun;40(3):91-93. doi: 10.18773/austprescr.2017.037. Epub 2017 Jun

Delco F, Michetti P, Beglinger C, et al. (2004) Health care resource utilization and costs of NSAID-induced gastrointestinal toxicity: a population-based study in Switzerland. Digestion; 69: 10-9.

Deshpande A, Pasupuleti V, Thota P, Pant C, Mapara S, Hassan S, Rolston D D, (2013)Sferra TJ, Hernandez A V. Acid-suppressive therapy is associated with spontaneous bacterial peritonitis in cirrhotic patients: A meta-analysis. J. Gastroenterol. Hepatol.; 28, 235-242.

Du Z, Liu Z, Ning Z, Liu Y, Song Z, Wang C, Lu A. (2015) Prospects of Boswellic acids as potential pharmaceutics.Planta Med. ;Mar;81(4):259-271. 
Ebrahimpour S, Fazeli M, Mehri S, Taherianfard M, Hosseinzadeh H. (2017) Boswellic Acid Improves cognitive function in a rat model through its antioxidant activity: - Neuroprotective effect of Boswellic acid. J Pharmacopuncture;20(1):10-17.

Falcão H S, Mariah I R, Diniz M F, Batista L M, Barbosa-Filho J M. (2008) Plants of the American continent with antiulcer activity. Phytomedicine;15, 132-146.

Farooq M, Haq I, Qureshi AS. (2008) Cardiovascular risks of COX inhibition: current perspectives. Expert Opin Pharmacother; 9: 1311-1319.

Forouzanfar F, Hosseinzadeh H, Ebrahimzadeh Bideskan A, Sadeghnia HR. (2016) Aqueous and Ethanolic Extracts of Boswellia serrata Protect Against Focal Cerebral Ischemia and Reperfusion Injury in Rats. Phytother Res.; Dec;30(12):1954-1967.

Frankowski H, Gu YH, Heo JH, Milner R, del Zoppo GJ. (2012) Use of gel zymography to examine matrix metalloproteinase (gelatinase) expression in brain tissue or in primary glial cultures. Methods Mol Biol.;814:221-233.

Ganguly K, Swarnakar S. (2012) Chronic gastric ulceration causes matrix metalloproteinases- 9 and-3 augmentation: alleviation by melatonin. Biochimie;94: 2687-2698.

Ganguly K, Kundu P, Banerjee A, Reiter RJ, Swarnakar S. (2006) Hydrogen peroxide-mediated downregulation of matrix metalloproteinase-2 in indomethacin-induced acute gastric ulceration is blocked by melatonin and other antioxidants. Free Rad Biol Med.; 41:911-925.

Gayathri B, Manjula N, Vinaykumar KS, Lakshmi BS, Balakrishnan A. (2007) Pure compound from Boswellia serrata extract exhibits anti-inflammatory property in human PBMCs and mouse macrophages through inhibition of TNFalpha, IL-1beta, NO and MAP kinases. Int Immunopharmacol.; Apr;7(4):473-482.

Gerbeth K, Hüsch J, Fricker G, Werz O, Schubert-Zsilavecz M, Abdel-Tawab M(2013) Fitoterapia. In vitro metabolism, permeation, and brain availability of six major Boswellic acids from Boswellia serrata gum resins.; Jan;84:99-106.

Gilard M, Arnaud B, Le Gal G, Abgrall J F, Boschat J. (2006) Influence of omeprazole on the antiplatelet action of clopidogrel associated to aspirin. J. Thromb. Haemost.; 4, 2508-2509.

Ghebremariam Y T, Lee J C, LePendu P, Erlanson D A, Slaviero A, Shah N H, Leiper J M, Cooke J P. (2014) Response to letters regarding article, "unexpected effect of proton pump inhibitors: Elevation of the cardiovascular risk factor asymmetric dimethylarginine". Circulation 2014; 129, e428. 
Graham DJ, Campen D, HuiR, et al. (2005) Risk of acute myocardial infarction and sudden cardiac death in patients treated with cyclo-oxygenase 2selective and non-selective non-steroidal anti-inflammatory drugs: a nested case-control study. Lancet; 365: 475-481.

Gerhardt, H.; Seifert, F.; Buvari, P.; Vogelsang, H.; Repges, R. (2001) Therapy of active Crohn disease with Boswellia serrata extract H 15.Z. Fur Gastroenterol. , 39, 11-17

Gupta I, Gupta V, Parihar A, Gupta S, Lüdtke R, Safayhi H, Ammon HP. (1998) Effects of Boswellia serrata gum resin in patients with bronchial asthma: results of a double-blind, placebo-controlled, 6-week clinical study. Eur J Med Res; 17;3(11):511-514.

Haroyan, A.; Mukuchyan, V.; Mkrtchyan, N.; Minasyan, N.; Gasparyan, S.; Sargsyan, A.; Narimanyan, M.; Hovhannisyan, A. (2018) Efficacy and safety of curcumin and its combination with boswellic acid in osteoarthritis: A comparative, randomized, double-blind, placebo-controlled study. BMC Complementary Altern. Med., 18, 7.

Hartmann RM, Fillmann HS, Martins MI, Meurer L, Marroni NP. (2014) Boswellia serrata has beneficial anti-inflammatory and antioxidant properties in a model of experimental colitis. Phytother Res.; Sep;28(9):1392-1398.

Henkel A, Tausch L, Pilling M, Jauch J, Karas M, Schneider G, Werz O. (2015) Boswellic acids target the human immune system-modulating antimicrobial peptide LL-37. Pharmacol. Res.; 102, 53-60.

Henkel A, Kather N, Mönch B, Northoff H, Jauch J, Werz O. (2012) Boswellic acids from frankincense inhibit lipopolysaccharide functionality through direct molecular interference. Biochem Pharmacol. Jan 1;83(1):115-121.

Holtmeier W, Zeuzem S, Preiss J, Kruis W, Böhm S, Maaser C, Raedler A, Schmidt C, Schnitker J, Schwarz J, Zeitz M, Caspary W. (2010) Randomized, placebo-controlled, double-blind trial of Boswellia serrata in maintaining remission of Crohn's disease: good safety profile but lack of efficacy. Inflamm Bowel Dis.;17:573-582.

Hüsch J, Bohnet J, Fricker G, Skarke C, Artaria C, Appendino G, SchubertZsilavecz M, Abdel-Tawab M. (2013) Enhanced absorption of Boswellic acids by a lecithin delivery form (Phytosome(®)) of Boswellia extract.Fitoterapia.; Jan;84:89-98.

Iram F, Khan SA, Husain A. (2017) Phytochemistry, and potential therapeutic actions of Boswellic acids: A mini-review. Asian Pac J Trop Biomed;7(6):513-523.

Jones R, Rubin G, Berenbaum F, et al. (2008) Gastrointestinal and cardiovascular risks of nonsteroidal anti-inflammatory drugs. Am J Med; 121: 464-474. 
Kar S, Subbaram S, Carrico PM, Melendez JA. (2010) Redox-control of matrix metalloproteinase-1: a critical link between free radicals, matrix remodeling, and degenerative disease. Respir Physiol Neurobiol; 31:299.

Kheloufi F, Frankel D, Kaspi E, Lepelley M, Mallaret M, Boucherie Q, Roll P, Micallef J. (2018) Chronic use of proton pump inhibitors, adverse events and potential biological mechanisms: A translational analysis.Therapie.; MayJunun;73(3):273-281.

Kirste, S.; Treier, M.; Wehrle, S.J.; Becker, G.; Abdel-Tawab, M.; Gerbeth, K.; Hug, M.J.; Lubrich, B.; Grosu, A.L.; Momm, F. (2011) Boswellia serrata acts on cerebral edema in patients irradiated for brain tumors: A prospective, randomized, placebo-controlled, double-blind pilot trial. Cancer , 117, 37883795.

Khosravi Samani M, Mahmoodian H, Moghadamnia A, Poorsattar Bejeh Mir A, Chitsazan M. (2011) The effect of Frankincense in the treatment of moderate plaque-induced gingivitis: a double-blinded randomized clinical trial. Daru.;19(4):288-294.

Kokkiripati PK, Bhakshu LM, Marri S, Padmasree K, Row AT, Raghavendra AS, Tetali SD. (2011) Gum resin of Boswellia serrata inhibited human monocytic (THP-1) cell activation and platelet aggregation. J Ethnopharmacol.; Sep 1;137(1):893-901.

Koivisto T T, Rautelin H I, Voutilainen M E, Heikkinen MT, Koskenpato J P, Färkkilä M A. (2005) First-line eradication therapy for Helicobacter pylori in primary health care based on antibiotic resistance: Results of three eradication regimens. Aliment. Pharmacol. Ther.; 21, 773-782.

Konturek PC, Brzozowski T, Karczewski E, Duda A, Bielański W, Hahn EG, Konturek SJ. (2000) Water extracts of Helicobacter pylori suppress the expression of histidine decarboxylase and reduce histamine content in the rat gastric mucosa. Digestion.;62(2-3):100-109.

Kwok C S, Arthur A K, Anibueze C I, Singh S, Cavallazzi R, Loke Y K. (2012) Risk of clostridium difficile infection with acid-suppressing drugs and antibiotics: Meta-analysis. Am. J. Gastroenterol.;107, 1011-1019.

Laine L, Ahnen D, McClain C, Solcia E, Walsh J H. (2000) Review article: Potential gastrointestinal effects of long-term acid suppression with proton pump inhibitors. Aliment. Pharmacol. Ther.; 14, 651-668.

Lanas A. (2016) We are using too many PPIs, and we need to stop: A European perspective. Am. J. Gastroenterol.; 111, 1085-1086.

Lanas A. (2008) Role of nitric oxide in the gastrointestinal tract.Arthritis Res Ther.;10 Suppl 2:S4. 
Langenbach R, Morham SG, Tiano HF, et al. (1995) Prostaglandin synthase one gene disruption in mice reduces arachidonic acid-induced inflammation and indomethacin-induced gastric ulceration. Cell.;83(3):483-492.

Lam J R, Schneider J L, Zhao W, Corley D A. (2013) Proton pump inhibitor and histamine two receptor antagonist use and vitamin B12 deficiency. JAMA; $310 ; 2435-2442$.

Lambert A A, Lam J O, Paik J J, Ugarte-Gil C, Drummond M B, Crowell TA. (2015) Risk of community-acquired pneumonia with outpatient proton-pump inhibitor therapy: A systematic review and meta-analysis. PLoS ONE; 10, e0128004.

Lew E A. (1999) Review article: Pharmacokinetic concerns in the selection of antiulcer therapy. Aliment. Pharmacol. Ther.; 13 (Suppl. S5), 11-16.

Li, X.J.; Yang, Y.J.; Li, Y.S.; Zhang, W.K.; Tang, H.B. (2016) alpha-Pinene, linalool, and 1-octanol contribute to the topical anti-inflammatory and analgesic activities of frankincense by inhibiting COX-2. J. Ethnopharmacol.; $179,22-28$

Li W, Zeng S, Yu LS, Zhou Q. (2013) Pharmacokinetic drug interaction profile of omeprazole with adverse consequences and clinical risk management.Ther Clin Risk Manag.;9:259-267.

May B, Banerjee D, Bandyopadhyay SK, Chattopadhyay S. (2009) Regulation of arginase/nitric oxide synthesis axis via cytokine balance contributes to the healing action of malabaricone $\mathrm{B}$ against indomethacin-induced gastric ulceration in mice.Int. Immunopharmacol. ;Apr;9(4):491-8

Merwat, S.N.; Spechler, S.J. (2009) Might the use of acid-suppressive medications predispose to the development of eosinophilic esophagitis? Am. J. Gastroenterol.; 104, 1897-1902. [CrossRef] [PubMed

Mostafa DM, Abd El-Alim SH, Kassem AA. (2017) Chapter 6 - Nanoemulsions: A New Approach for Enhancing Phytonutrient Efficacy. Nanotechnology Applications in Food Flavor, Stability, Nutrition and Safety,;107-127.

Mostafa DM, Ammar NM, Abd El-Alim SH, Kassem AA, Hussein RA, Awad G, El-Awdan SA. (2015) Boswellia carterii liquisolid systems with promoted anti-inflammatory activity. Curr Drug Deliv. ; 12(4):454-63

Motawi, T. K., Abd Elgawad, H. M. \& Shahin, N. N. (2008) Gastroprotective effect of leptin in indomethacin-induced gastric injury. J. Biomed. Sci.; 15, 405-412

Morikawa T, Matsuda H, Yoshikawa M. A (2017) Review of Anti-inflammatory Terpenoids from the Incense Gum Resins Frankincense and Myrrh. J Oleo Sci.; Aug 1;66(8):805-814. doi: 10.5650/jos.ess16149. Epub 2017 Apr 4. 
Moussaieff A, Mechoulam R.. (2009) Boswellia resin: from religious ceremonies to medical uses; a review of in-vitro, in-vivo, and clinical trials. J Pharm Pharmacol.; Oct;61(10):1281-93. DOI: 10.1211/jpp/61.10.0003.

Nafeeza M. I., Fauzee A. M., Kamsiah J., Gapor M. T. (2002) Comparative effects of a tocotrienol-rich fraction and tocopherol in aspirin-induced gastric lesions in rats. Asia Pacific Journal of Clinical Nutrition.;11(4):309-313. DOI: 10.1046/j.1440-6047.2002.00298.x.

Naito Y, Yoshikawa T, Yoshida N, et al. (1998) Role of oxygen radicals and lipid peroxidation in indomethacin-induced gastric mucosal injury. Dig Diss Sci.;43:30-34

Narayanan, M.; Reddy, K.M.; Marsicano, E. (2018) Peptic ulcer disease, and Helicobacter pylori infection. Mo. Med.; 115, 219-224.

Notarnicola, A.; Maccagnano, G.; Moretti, L.; Pesce, V.; Tafuri, S.; Fiore, A.; Moretti, B. (2016) Methylsulfonylmethane and boswellic acids versus glucosamine sulfate in the treatment of knee arthritis: Randomized trial. Int. J. Immunopathol. Pharmacol. , 29, 140-146.

Notarnicola, A.; Tafuri, S.; Fusaro, L.; Moretti, L.; Pesce, V.; Moretti, B. (2011) The "MESACA" study: Methylsulfonylmethane and boswellic acids in the treatment of gonarthrosis. Adv. Ther. , 28, 894-906

Nur Azlina M. F., Kamisah Y., Chua K. H., Ibrahim I. A. A., Qodriyah H. M. S. (2015) Preventive effects of tocotrienol on stress-induced gastric mucosal lesions and its relation to oxidative and inflammatory biomarkers. PloS ONE.;10(10) DOI: 10.1371/journal.pone.0139348.e0139348.

Palle, S.; Kanakalatha, A.; Kavitha, C.N. (2018) Gastroprotective and antiulcer effects of Celastrus paniculatus seed oil against several gastric ulcer models in rats. J. Diet. Suppl.;15, 373-385.

Piao X, Li S, Sui X, et al. (2018) 1-deoxynojirimycin (DNJ) ameliorates indomethacininduced gastric ulcers in mice by affecting the NF-kappaB signaling pathway. Front Pharmacol.;9:372.15

Poeckel D, Werz O. (2006) Boswellic acids: biological actions and molecular targets. Curr Med Chem;13(28):3359-69.

Rahal A, Kumar A, Singh V, Yadav B, Tiwari R, Chakraborty S, Dhama K (2014) Oxidative stress, prooxidants, and antioxidants: the interplay. BioMed Res Int ;ID 761264:19 p.

Rates, S.M. (2001) Plants as a source of drugs. Toxicon, , 39, 603-613. 
Repetto, M.G., and Llesuy S.F. (2002) Antioxidant properties of natural compounds used in popular medicine for gastric ulcers. Braz. J. Med. Biol. Res.,; 35: 523534.

Riva A, Allegrini P, Franceschi F, Togni S, Giacomelli L, Eggenhoffner R. (2017) A novel Boswellia acids delivery form (Casperome ${ }^{\circledR}$ ) in the management of musculoskeletal disorders: a review.Eur Rev Med Pharmacol Sci. Nov;21(22):5258-5263. DOI: 10.26355/eurrev_201711_13849

Roy NK1, Parama D1, Banik K1, Bordoloi D1, Devi AK1, Thakur KK1, Padmavathi G1, Shakibaei M2, Fan L3, Sethi G4, Kunnumakkara AB. (2019) An Update on Pharmacological Potential of Boswellic Acids against Chronic Diseases. Int J Mol Sci. Aug 22;20(17). PII: E4101. DOI: 10.3390/ijms20174101

Sabra SM, Al-Masoudi LM. (2014) The effect of using frankincense (Boswellia sacra) chewing gum on the microbial contents of buccal/oral cavity, Taif, KSA. J Dent Med Sci;13:77-82

Safayhi H, Rall B, Sailer ER, Ammon HP. (1997) Inhibition by Boswellic acids of human leukocyte elastase. J Pharmacol Exp Ther.;28 (1):460-3.

Safayhi H, Sailer ER, Ammon HP. (1996) 5-Lipoxygenase inhibition by acetyl-11keto- $\beta$-boswellic acid (AKBA) by a novel mechanism. Phytomedicine. May;3(1):71-2. DOI: 10.1016/S0944-7113(96)80013-4.

Sengupta, K.; Alluri, K.V.; Satish, A.R.; Mishra, S.; Golakoti, T.; Sarma, K.V.; Dey, D.; Raychaudhuri, S.P. A (2008) double blind, randomized, placebo controlled study of the efficacy and safety of 5-Loxin for treatment of osteoarthritis of the knee. Arthritis Res. Ther. , 10, R85.

Shimada T., Koitabashi A., Fujii Y., et al. (2004) PPAR $\gamma$ mediates NSAIDs-induced upregulation of TFF2 expression in gastric epithelial cells. FEBS Letters.;558(1-3):33-38. DOI: 10.1016/S0014-5793(03)01527-8

Sharma A, Gupta NK, Dixit VK. (2010) Complexation with phosphatidylcholine as a strategy for absorption enhancement of boswellic acid. Drug Deliv. Nov;17(8):587-95. doi: 10.3109/10717544.2010.501461

Shah BA1, Qazi GN, Taneja SC. (2009) Boswellic acids: a group of medicinally important compounds. Nat Prod Rep. Jan;26(1):72-89.

Skarke C, Kuczka K, Tausch L, Werz O, Rossmanith T, Barrett JS, Harder S, Holtmeier W, Schwarz JA. (2012) Increased bioavailability of 11-keto- $\beta$ boswellic acid following single oral dose frankincense extract administration after a standardized meal in healthy male volunteers: modeling and simulation considerations for evaluating drug exposures.; J Clin Pharmacol. Oct;52(10):1592-600. Epub 2011 Dec 13. 
Siemoneit U, Koeberle A, Rossi A, Dehm F, Verhoff M, Reckel S, Maier TJ, Jauch J, Northoff H, Bernhard F, Doetsch V, Sautebin L, Werz O. (2011) Inhibition of microsomal prostaglandin E2 synthase-1 as a molecular basis for the anti-inflammatory actions of Boswellic acids from frankincense. $\mathrm{Br} \mathrm{J}$ Pharmacol. Jan;162(1):147-62. DOI: 10.1111/j.1476-5381.2010.01020.x

Siemoneit U, Hofmann B, Kather N, Lamkemeyer T, Madlung J, Franke L, Schneider G, Jauch J, Poeckel D, Werz O. (2008) Identification and functional analysis of cyclooxygenase-1 as a molecular target of Boswellic acids. Biochem Pharmacol. Jan 15;75(2):503-13. Epub 2007 Sep 14.

Silverstein F, Faith G, Goldstein JL, et al. (2000) Gastrointestinal toxicity with celecoxib vs. nonsteroidal anti-inflammatory drugs for osteoarthritis and rheumatoid arthritis. The CLASS Study: a randomized controlled trial. JAMA; 284: $1247-55$

Singh L.P, Sharma A.V, Swarnakar S; (2011) Upregulation of collagenase-1 and -3 in indomethacin-induced gastric ulcer in diabetic rats: role of melatonin. J Pineal Res. 2011; Aug;51(1):61-74. DOI: 10.1111/j.1600-079X.2010.00845.x. Epub Feb 23.

Singh, S.; Khajuria, A.; Taneja, S.C.; Khajuria, R.K.; Singh, J.; Johri, R.K.; Qazi, G.N. (2008) The gastric ulcer protective effect of Boswellic acids, a leukotriene inhibitor from Boswellia serrata, in rats. Phytomedicine: Int. J. Phytother. Phytopharm., 15, 408-415

Spechler S J. (2019) Proton pump inhibitors: What the internist needs to know. Med. Clin. N. Am.; 103, 1-14.

Sterk V, Buchele B, Simmet T. (2004) Effect of food intake on the bioavailability of Boswellic acids from a herbal preparation in healthy volunteers. Planta Med;70:1155-1160.

Suleyman H1, Albayrak A, Bilici M, Cadirci E, Halici Z; (2010) Different mechanisms in the formation and prevention of indomethacin-induced gastric ulcers. Inflammation. Aug;33(4):224-34. DOI: 10.1007/s10753-009-9176-5.

Suleyman H, Demircan B, Karagoz Y. (2007) Anti-inflammatory and side effects of cyclo-oxygenase inhibitors. Pharmacol Rep.;59:247

Syrovets T, Gschwend JE, Buchele B, Laumonnier Y, Zugmaier W, Ganze F, Simmet T. (2005) Inhibition of IкB Kinase activity by acetyl Boswellic Acids promotes apoptosis in androgen-independent PC-3 prostate cancer cells in vitro and in vivo. J Biol Chem;280:6170- 6180

Szabo S, Khomenko T, Gombos Z, Deng XM, Jadus MR, Yoshida M. (2000) Review article: transcription factors and growth factors in ulcer healing.Aliment Pharmacol Ther.; Apr;14 Suppl 1:33-43. 
Tarnawski AS, Ahluwalia A, (2012) Molecular mechanisms of epithelial regeneration and neovascularization during healing of gastric and esophageal ulcers. Curr Med Chem.;19(1):16-27.

Togni, S.; Maramaldi, G.; Di Pierro, F.; Biondi, M. (2014) A cosmeceutical formulation based on boswellic acids for the treatment of erythematous eczema and psoriasis. Clin. Cosmet. Investig. Derm. , 7, 321-327.

Umar S1, Umar K2, Sarwar AH3, Khan A4, Ahmad N5, Ahmad S5, Katiyar CK6, Husain SA7, Khan HA. (2014) Boswellia serrata extract attenuates inflammatory mediators and oxidative stress in collagen induced arthritis. Phytomedicine. May 15;21(6):847-56. doi: 10.1016/j.phymed.2014.02.001. Epub 2014 Mar 22

Verhoff M1, Seitz S, Paul M, Noha SM, Jauch J, Schuster D, Werz O. (2014) Tetraand pentacyclic triterpene acids from the ancient anti-inflammatory remedy frankincense as inhibitors of microsomal prostaglandin E(2) synthase-1. J Nat Prod. Jun 27;77(6):1445-51. doi: 10.1021/np500198g. Epub 2014 May 20.

Verma S1, Kesh K1, Ganguly N1, Jana S1, Swarnakar S. (2014) Matrix metalloproteinases, and gastrointestinal cancers: Impacts of dietary antioxidants. World J Biol Chem. Aug 26;5(3):355-76. DOI: 10.4331/wjbc.v5.i3.355.

Vitor J.M.B. and Vale F.F. (2011) Alternative therapies for Helicobacter pylori: Probiotics and Phytomedicine. FEMS. Immunol. Med. Microbiol.,;63: 153164.

Wallace J. L. (2000) How do NSAIDs cause ulcer disease? Best Practice \& Research Clinical Gastroenterology.;14(1):147-159. DOI: 10.1053/bega.1999.0065

Wallace JL1, Miller MJ. (2000) Nitric oxide in mucosal defense: a little goes a long way. Gastroenterology. Aug;119(2):512-20

Wallace J. L., Tigley A. W. (1995) new insights into prostaglandins and mucosal defense. Alimentary Pharmacology \& Therapeutics.;9(3):227-235. DOI

Wallace, J.L., McKnight G.W., Keenan C.M., Byles N.I. (1990) And MacNaughton W.K. Effects of leukotrienes on the susceptibility of the rat stomach to damage and investigation of the mechanism of action. Gastroenterology.;98: 1178-1186

Wang M, Chen M, Ding Y, Zhu Z, Zhang Y, Wei P, Wang J, Qiao Y, Li L, Li Y, Wen A. (2015) Pretreatment with $\beta$-Boswellic Acid Improves Blood Stasis Induced Endothelial Dysfunction: Role of eNOS Activation. Sci Rep. Oct 20;5:15357. doi: 10.1038/srep15357 
Wroblewski LE, Peek M, (2010) Wilson KT.Helicobacter pylori and gastric cancer: factors that modulate disease risk. Clin Microbiol Rev.; 23:713739PubMedPubMedCentralCrossRefGoogle Scholar.

Yepuri G, Sukhovershin R, Nazari-Shafti TZ, Petrascheck M, Ghebre YT, Cooke JP. (2016) Proton Pump Inhibitors Accelerate Endothelial Senescence. Circ Res. ;Jun 10;118(12):e36-42.

Zhang, Y.; Jia, J.; Ding, Y.; Ma, Y.; Shang, P.; Liu, T.; Hui, G.; Wang, L.; Wang, M.; Zhu, Z.; et al. (2016) Alpha-boswellic acid protects against ethanolinduced gastric injury in rats: Involvement of nuclear factor erythroid-2-related factor 2/heme oxygenase-1 pathway. J. Pharm. Pharmacol., 68, 514-522.

$$
\begin{aligned}
& \text { دور حمض البزوليك في علاج قرحه المعده } \\
& \text { مي محي الدين شريف *'،رحاب كامل'، انجي المرسي'، شريفه كامل احمد' } \\
& \text { البعبه السميه المزمنه، الهيئه القوميه للرقابه و البحوث الدو ائيه:' }
\end{aligned}
$$

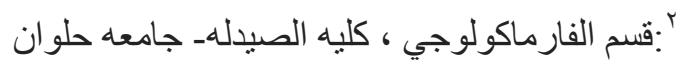

$$
\begin{aligned}
& \text { القرحة الهضمية مرض مزمن يعتمد على وجود عصير } \\
& \text { المعدة ودرجة الحموضةالدفاعات المخاطية. العقاقير المضادة للالتهابات غير الستيرويدية (مضادات الالتهاب غير } \\
& \text { الستيروئيدية) و Hبيلوري } \\
& \text { العدوى هما العاملان الرئيسيان لتعطيل المقاومة المخاطية للإصـابة. تقليدي }
\end{aligned}
$$

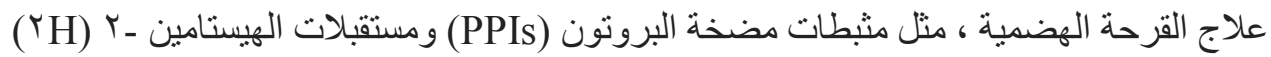

$$
\begin{aligned}
& \text { الخصوم ، أظهروا تأثيرات ضارة وانتكاسات وتفاعلات دو ائية مختلفة. هناك كان الاهتمام المتز ايد في العلاجات } \\
& \text { البديلة واستخدام المنتجات العشبية. أحماض Boswellic } \\
& \text { توفير بديل محتمل لعلاج العقاقير المضادة للالتهابات غير الستيرويدية المستحثة } \\
& \text { القرحة الهضمية. }
\end{aligned}
$$

